\title{
EFFICACY OF ALTERNATIVE COPPER-BASED PRESERVATIVES IN PROTECTING DECKING FROM BIODEGRADATION
}

\author{
Stan T. Lebow ${ }^{1, \wedge}$, Katie M. Ohno ${ }^{1}$, Patricia K. Lebow ${ }^{1}$, Michael H. West ${ }^{2}$
}

\begin{abstract}
The above-ground performance of decking treated with two alternative copper-based preservative formulations is being evaluated at a test site near Madison, Wisconsin, USA. Southern pine sapwood lumber specimens ( $38 \mathrm{~mm}$ by $140 \mathrm{~mm}$ by $910 \mathrm{~mm}$ ) were pressure treated with $0,93 \%, 1,40 \%$ or $2,34 \%$ (oxide basis) actives concentrations of a boron-copper formulation (BC) composed of 7,2 \% copper hydroxide and 92,8 $\%$ sodium tetraborate decahydrate. Similar specimens were pressure-treated with $0,66 \%$ or $1,32 \%$ actives concentrations of a copper-zinc formulation (CZDP) composed of $18 \%$ copper (CuO basis), $12 \%$ zinc ( $\mathrm{ZnO}$ basis), $14 \%$ dimethylcocoamine and $56 \%$ propanoic acid. In both cases untreated specimens and specimens treated with a $1 \%$ concentration of chromated copper arsenate Type C (CCA-C) were included for comparison. The specimens were installed on racks approximately $760 \mathrm{~mm}$ above the ground and periodically evaluated for extent of fungal decay and surface microbial growth. After 18 years in test specimens treated with the lowest solution concentration of BC $(0,93 \%)$ suffered substantial degradation and all but three replicates have failed. Obvious decay has not yet been detected in specimens treated to the highest $\mathrm{BC}$ concentration $(2,34 \%)$, but decay is suspected in one of these specimens. Decking specimens treated with CZDP exhibited no evidence of decay until year 17 when a fruiting body was observed on one specimen treated with a $0,66 \%$ solution concentration. There has been no evidence of decay in specimens treated with 1,32\% CZDP or in either set of specimens treated with $1 \%$ CCA-C. Both BC and CZDP-treated specimens were at least as effective as $1 \%$ CCA-C in minimizing noticeable surface microbial growth. These decking studies confirm that relatively low copper concentrations can provide substantial protection for decking exposed in a moderate climate, and that the CZDP formulation is potentially more effective than the $\mathrm{BC}$ formulation. However, caution is warranted in extrapolating these findings to more severe climates and to construction designs that are more likely to trap moisture.
\end{abstract}

Keywords: Above-ground, copper, decking, durability, wood preservatives.

\section{INTRODUCTION}

There is continued interest in development of economical, effective and low toxicity wood preservative formulations, particularly for residential applications where the majority of treated wood is used above-ground. Copper has been used in wood preservatives for over a century and remains a common component in current formulations (Freeman and McIntyre 2008). Unlike carbon-based preservatives, copper is not biodegraded and retains is efficacy for long periods. However, copper is not effective against all types of fungi. Some mold/ stain fungi can grow on copper-treated wood, and certain types of decay fungi are classified as "copper-tolerant" (Ohno et al. 2015, Ohno 2016). These fungi can sporadically cause severe and rapid damage in wood treated with copper, and thus commercial copper-based preservatives typically include a co-biocide such as arsenic, quaternary ammonium compounds, triazoles, or naphthenic acids to provide additional protection. Zinc has also been widely used as a component of wood preservative formulations. Zinc chloride was commonly used for pressure-treatment of railroad ties in the early 1900's but provided only a moderate increase in durability. Zinc-meta-arsenite was used for treatment of poles and timbers in the late 1920's through the 
1930's and was at one time standardized by the American Wood Protection Association (Lebow and Anthony 2012). Chromated zinc chloride was standardized by the AWPA until 1992, when it was removed from the standards for lack of use. Combinations of zinc and copper have also been evaluated (Rak and Unligl 1978) and a formulation of ammoniacal copper zinc arsenate (ACZA) is currently standardized for treatment of poles, piles and timbers in the United States (AWPA 2019). In general, zinc is a less effective fungicide than copper, but when used at sufficient concentrations it provides adequate protection, especially for applications out of ground contact (Barnes et al. 2004, De Groot and Stroukoff 1998). Zinc solutions have the advantages of being colorless, and in causing less corrosion to metal fasteners than copper-based formulations. Boron is a third element commonly used in wood preservatives. Borates have relatively low toxicity to humans and the environment and are effective in preventing attack by decay fungi and termites (Ahmed et al. 2004, Drysdale 1994, Manning 2008). Unfortunately, borates are not chemically bound to the wood, and thus can be leached out of the wood in external exposures. This disadvantage can be partially overcome by selection of appropriate end-use applications, and by the incorporation of a less-leachable co-biocide. It should be noted that in some applications the solubility of boron can also be an advantage because it allows the boron to diffuse more deeply into untreated wood. Treatment by diffusion plays a key role when boron is applied externally to the ground line area of utility poles (Lebow et al. 2014) or used as a dip treatment for green railroad ties (Taylor and Lloyd 2009). This paper discusses above-ground evaluation of the efficacy two alternative wood preservative formulations based on combinations of copper with one or more co-biocides.

One of the preservatives is formulated with an active ingredient composition of $7,2 \%$ technical copper hydroxide and $92,8 \%$ sodium tetraborate decahydrate (10 mole borax). This preservative, herein referred to as $\mathrm{BC}$, is currently in commercial use as a thickened paste for remedial treatment to protect the ground-line area of utility poles (Lebow et al. 2014). However, the performance of BC as a ground line treatment does not necessarily ensure its performance as a pressure-treatment preservative. Preservatives for pressure treatment must be diluteable in water or other solvent and able to penetrate into the wood during treatment. This research has been conducted and indicates that $\mathrm{BC}$ is adaptable to pressure treatment (Lebow et al. 2005a) and is effective in protecting wood against decay and termites in laboratory and covered ground proximity tests Lebow et al. 2005b, Lebow et al. 2006, Woodward et al. 2002). However, laboratory leaching tests also indicated that 45 $\%-55 \%$ of the boron and $5 \%-6 \%$ of copper was depleted from specimens during exposure to $750 \mathrm{~mm}$ of simulated rainfall (Lebow et al. 2009). This suggests that boron could be largely depleted from wood exposed to precipitation after a few years in areas with moderate rainfall or even more rapidly in wet climates.

Other aspects of adapting BC to use as a pressure treatment preservative, particularly for wood exposed outdoors, have not been fully evaluated. Permanence of the boron and copper in the treated wood is a consideration and it is expected that the type of outdoor exposure (above-ground versus ground-contact) will affect both efficacy and permanence. Stake tests installed in Mississippi and Wisconsin indicated that BC does not provide adequate protection at the concentrations evaluated (Lebow et al. 2009). Failures were particularly rapid at the Mississippi test site and appeared to be associated with boron depletion and subsequent colonization by copper-tolerant fungi. It should be noted that the stakes used in that study were $19 \mathrm{~mm}$ by $19 \mathrm{~mm}$ by $457 \mathrm{~mm}$, and that these small dimensions likely contributed to rapid boron depletion (Lebow et al. 2009).

Copper zinc dimethylcocoamine propanoic acid (CZDP) is composed of $18 \%$ copper (CuO basis), $12 \%$ zinc ( $\mathrm{ZnO}$ basis), $14 \%$ dimethylcocoamine and $56 \%$ propanoic acid. This formulation was developed to mitigate attack by copper-tolerant fungi and to lessen concerns with corrosion (West 2004, Williams et al. 1994). Previous research has shown that fatty amine salts can inhibit decay by some types of fungi (Butcher et al. 1977, Preston 1983). Propanoic (propionic) acid was also used in the formulation, primarily to improve solubility. However, propanoic acid does have efficacy against mold fungi in crop storage and food products, (Sheaffer and Clark 1975, Suhr and Nielsen 2004) and may also contribute to preservative performance (Clausen et al. 2010). As with BC, the efficacy of CZDP was initially evaluated with ground-contact stake tests installed at a test site in southern Mississippi. Although most stakes at higher retentions remained in good condition after seven years, sporadic failures occurred in all but the highest retention (Lebow et al. 2012). The sporadic nature of the fungal attack, and the observation of a fungus thought to be a strain of Fibroporia (Antrodia) radiculosa (Peck) Parmasto suggests the failures were caused by copper-tolerant fungi.

Although neither of these formulations provided adequate protection for wood placed in contact with the ground (Lebow et al. 2009, Lebow et al. 2012), above-ground exposure typically represents a much less severe biodeterioration hazard (Kirker and Winandy 2014). In addition, ground-contact failures in both formulations appeared to be at least partially associated with copper-tolerant fungi, and there is some evidence that there is less risk of degradation by copper-tolerant fungi in treated wood used above ground (Choi et al. 2002). This paper reports on continuing research to evaluate the potential use of BC and CZDP treatments for above- 
ground applications such as decking. Pressure-treated decking specimens were exposed at a test site near Madison, Wisconsin and were periodically evaluated during exposure for either 18 years (BC) or 17 years (CZDP).

\section{MATERIALS AND METHODS}

Decking specimens $(0,91 \mathrm{~m}$ in length) were prepared from $38 \mathrm{~mm}$ by $140 \mathrm{~mm}$ ( 2 in. by 6 in. nominal) southern pine lumber free of heartwood, large knots or other large defects. The specimens were then conditioned to constant weight in a room maintained at $74^{\circ} \mathrm{F}\left(23^{\circ} \mathrm{C}\right)$ and $65 \%$ relative humidity prior to pressure treatment. This procedure was followed for both the BC and CZDP decking evaluations, but the studies were initiated a year apart. Twelve or ten replicate specimens per treatment group were used for the BC and CZDP evaluations, respectively.

Three BC solution concentrations $(0,93 \%, 1,40 \%$ or $2,34 \%$, oxide basis) were used for pressure treatment (see Table 1 for borate and copper concentrations). An additional set of specimens was treated with a formulation of $1,4 \% \mathrm{BC}$ plus $10 \%$ sodium silicate to evaluate whether the silicate would impart water repellency, potentially minimizing checking and/or slowing the leaching of borate from the wood. Two CZDP solution concentrations $(0,66 \%$ and $1,32 \%$, oxide basis) were evaluated (Table 2$)$. A set of specimens treated with a $1 \%$ chromated copper arsenate (CCA-C) solution was also included in each test to serve as a positive control (Table 1, Table 2).

All treatments were conducted using a full-cell pressure process. The initial vacuum was maintained at $-75 \mathrm{kPa}$ (gauge) for $30 \mathrm{~min}$; the pressure was maintained at $1,03 \mathrm{MPa}$ (gauge) for 1 hour. The 2,34 \% $\mathrm{BC}$ treatment was conducted with a solution heated to approximately $50{ }^{\circ} \mathrm{C}$ to improve solubility, while the remaining $\mathrm{BC}, \mathrm{CZDP}$ and CCA treatments were conducted at room temperature. Each specimen was weighed before and after treatment to determine solution uptake and allow calculation of uptake retention (Table 3, Table 4). It was noted that the sodium silicate interfered with solution uptake, causing a lower preservative retention in the 1,4 $\% \mathrm{BC}$ plus sodium silicate specimens.

Table 1: Active ingredient concentrations in solutions used for $\mathrm{BC}$ decking evaluation.

\begin{tabular}{|c|c|c|c|c|c}
\hline Treatment Solution & $\% \mathrm{~B}$ as $\mathrm{B}_{2} \mathrm{O}_{3}$ & $\% \mathrm{Cu}$ as $\mathrm{CuO}$ & $\% \mathrm{Na}_{4} \mathrm{SiO}_{4}$ & $\% \mathrm{Cr}$ as $\mathrm{CrO}_{3}$ & $\% \mathrm{As}_{\text {as }} \mathrm{As}_{2} \mathrm{O}_{5}$ \\
\hline $0,93 \% \mathrm{BC}$ & 0,32 & 0,05 & - & - & - \\
\hline $1,40 \% \mathrm{BC}$ & 0,48 & 0,08 & - & - & - \\
\hline $\begin{array}{c}1,40 \% \mathrm{BC}+ \\
\text { sodium silicate }\end{array}$ & 0,48 & 0,08 & 10 & - & - \\
\hline $2,34 \% \mathrm{BC}$ & 0,80 & 0,13 & - & - & - \\
\hline $1 \% \mathrm{CCA}-\mathrm{C}$ & - & 0,18 & - & 0,47 & 0,35 \\
\hline Untreated & - & - & - & - & - \\
\hline
\end{tabular}

Table 2: Active ingredient concentrations in solutions used for CZDP decking evaluation.

\begin{tabular}{|l|c|c|c|c|}
\hline Treatment Solution & $\% \mathrm{Cu}$ as $\mathrm{CuO}$ & $\% \mathrm{Zn}$ as $\mathrm{ZnO}$ & $\%$ Dimethylcocoamine & $\%$ Propionic acid \\
\hline $0,66 \%$ CZDP & 0,12 & 0,08 & 0,09 & 0,37 \\
\hline $1,32 \%$ CZDP & 0,24 & 0,16 & 0,18 & 0,74 \\
\hline $1 \%$ CCA-C & See Table 1 for CCA-C actives concentrations \\
\hline Untreated & - & - & - & - \\
\hline
\end{tabular}

Table 3: Retention (based on net uptake) of active ingredients in wood for solutions used in BC decking evaluation.

\begin{tabular}{|l|c|c|c|c|c}
\hline & \multicolumn{5}{|c}{ Retention in Wood $\left(\mathrm{kg} / \mathrm{m}^{3}\right)$ Based on Uptake } \\
\hline Treatment Solution & $\mathrm{B}$ as $\mathrm{B}_{2} \mathrm{O}_{3}$ & $\mathrm{Cu}$ as CuO & $\mathrm{Na}_{4} \mathrm{SiO}_{4}$ & $\mathrm{Cr}_{\text {as }} \mathrm{CrO}_{3}$ & $\mathrm{As}_{\text {as } \mathrm{As}_{2} \mathrm{O}_{5}}$ \\
\hline $0,93 \% \mathrm{BC}$ & $1,33(0,72)$ & $0,21(0,11)$ & & & \\
\hline $1,40 \% \mathrm{BC}$ & $2,67(0,37)$ & $0,44(0,06)$ & & & \\
\hline $\begin{array}{l}1,40 \% \mathrm{BC}+\text { Sodium } \\
\text { silicate }\end{array}$ & $1,44(0,57)$ & $0,24(0,09)$ & $29,98(11,78)$ & & \\
\hline $2,34 \% \mathrm{BC}$ & $4,24(0,47)$ & $0,69(0,08)$ & & & \\
\hline $1 \%$ CCA-C & - & $1,10(0,05)$ & & $2,86(0,13)$ & $2,13(0,10)$ \\
\hline
\end{tabular}

Values in parenthesis represent one standard deviation from the mean. 
Table 4: Retention (based on net uptake) of active ingredients in wood for solutions used in CZDP decking evaluation. $\mathrm{V}$

\begin{tabular}{|l|c|l|l|l|l|l|}
\hline & \multicolumn{6}{|c|}{ Retention in Wood $\left(\mathrm{kg} / \mathrm{m}^{3}\right)$ Based on Uptake } \\
\hline $\begin{array}{l}\text { Treatment } \\
\text { Solution }\end{array}$ & $\mathrm{Cu}$ as $\mathrm{CuO}$ & $\mathrm{Zn}$ as $\mathrm{ZnO}$ & $\begin{array}{l}\text { Dimethyl- } \\
\text { cocoamine }\end{array}$ & $\begin{array}{l}\text { Propionic } \\
\text { acid }\end{array}$ & $\mathrm{Cr}$ as $\mathrm{CrO}_{3}$ & $\mathrm{As}_{\text {as } \mathrm{As}_{2} \mathrm{O}_{5}}$ \\
\hline $0,66 \%$ CZDP & $0,70(0,04)$ & $0,46(0,03)$ & $0,52(0,03)$ & $2,14(0,13)$ & & \\
\hline $1,32 \% \mathrm{CZDP}$ & $1,41(0,08)$ & $0,94(0,05)$ & $1,06(0,06)$ & $4,36(0,24)$ & & \\
\hline $1 \% \mathrm{CCA}-\mathrm{C}$ & $1,04(0,08)$ & & & & $2,73(0,20)$ & $2,03(0,15)$ \\
\hline
\end{tabular}

Values in parenthesis represent one standard deviation from the mean.

The decking specimens were installed in an open field at a test plot near Madison, Wisconsin, in November 2001 (BC specimens) or November 2002 (CZDP specimens). The location is characterized by cold winter months and warm, somewhat humid summers. It has a Scheffer Decay Hazard Index of 43,6 (Carll 2009). The specimens were supported on CCA-C treated wooden racks approximately $760 \mathrm{~mm}$ above the ground and fastened to the support by driving a single stainless-steel deck screw through the center of each specimen 152 $\mathrm{mm}$ from each end.

The specimens were periodically evaluated for decay and surface microbial growth (mold/mildew). Decay ratings were assigned by visually inspecting all sides of the specimens as well as gently prodding the end-grain and other areas for evidence of softening. A five-point rating scale $(4,3,2,1,0)$ was used to express the extent of decay. In our experience the commonly used 10, 9, 8, 7, 6, 4, 0 rating criteria described for many AWPA evaluation standards (AWPA 2019) is not readily applicable to above-ground decking tests in moderate climates. The AWPA ratings correspond to percent of cross-section decayed, but because decay in decking specimens develops internally the percent of cross-section affected cannot be determined without destroying the specimen. We adapted the decay rating system to correspond to examination of the outside of the specimens. ratings were assigned as 4 (no evidence of decay); 3 (decay suspected); 2 (obvious decay); 1 (severe decay); or 0 (easily broken along or across the grain). The presence of even a single decay fungus fruiting body on any surface was considered obvious decay.

The presence of surface mold or mildew did not influence the decay rating unless it was accompanied by other signs of decay. However, because surface appearance can be an important component of how consumers view decking durability, the non-decayed specimens were also visually evaluated for surface microbial growth. Only the upper surface that would be visible to the consumer was evaluated for appearance. The microbial growth evaluation was a binary "yes" or "no" response to the question of whether a consumer might find that extent of growth noticeable and objectionable. Both area of microbial coverage and visibility (generally darkness) were considered. It is recognized that this is a subjective assessment.

\section{RESULTS AND DISCUSSION}

\section{BC decking}

The decay resistance of $\mathrm{BC}$ decking was a clearly influenced by preservative retention. The untreated specimens begin to exhibited evidence of decay within 3 years and had all failed within 10 years (Figure 1). Specimens treated with the lowest solution concentration $(0,93 \%)$ suffered substantial degradation and all but three replicates have failed. Obvious decay has not yet been detected in specimens treated to the highest concentration (2,34\%), although one specimen was rated as " 3 " at the year 18 inspection because of suspicion of decay (Figure 1). Specimens treated with the 1,4\% BC concentration have suffered some degradation, and this was particularly apparent for the formulation that included sodium silicate. The sodium silicate apparently interfered with preservative uptake during treatment, possibly resulting in lower boron and/or copper retentions in the wood (Table 3). Not surprisingly, no evidence of decay has been observed in the specimens treated with the $1 \%$ CCA-C solution. 




Figure 1: Average decay ratings for untreated, BC-treated or CCA-treated specimens. Values adjacent to data points show cumulative number of failed specimens (if any).

Surface microbial growth was poorly correlated with preservative type or retention. All specimens exhibited some degree of mold growth, with frequency increasing over time (Figure 2). Specimens treated with the highest $(2,34 \%) \mathrm{BC}$ concentration appeared to have slightly less surface growth than those treated with $1 \%$ CCA at 18 years but both treatments did allow substantial growth. The sodium silicate addition to BC appeared to lessen the extent of surface discoloration to some extent but this was difficult to evaluate in later stages of the study because of decay development.

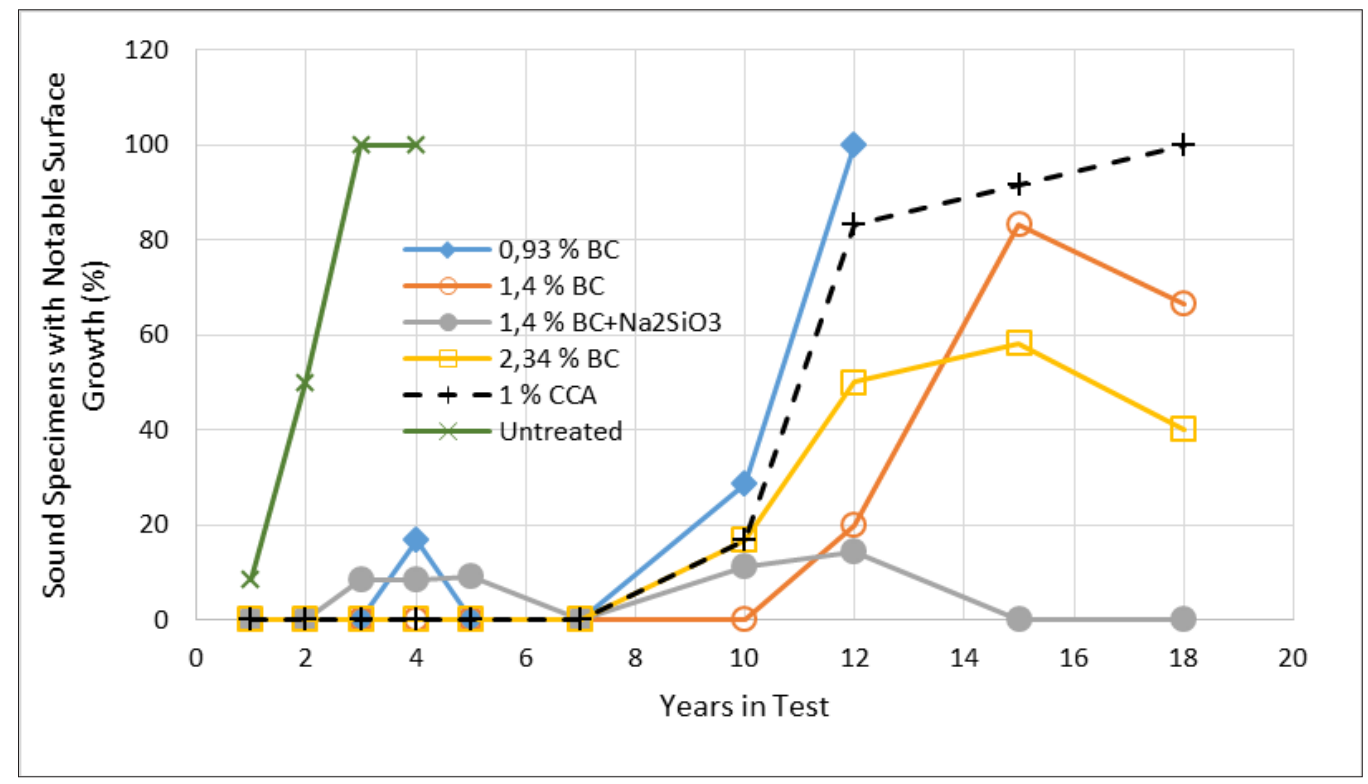

Figure 2: Percent of untreated, BC-treated or CCA-treated specimens with notable non-decay surface microbial growth at each inspection. 
Comparison of decay development in decking in this study to that of Mississippi in-ground stake specimens from an earlier report (Lebow et al. 2009) shows the great difference in decay hazard between the types of exposure and exposure locations (Table 5). For example, decay was not detected in any decking specimens treated with $2,34 \% \mathrm{BC}$ until year 18, while this condition was reached within the first year in the Mississippi stake exposure. A part of this difference can be attributed to the difficulty of detecting internal decay in the larger decking specimens. Decay is readily observed between the wood/soil interfaces stakes while decay in decking specimens often develops internally and can be difficult to detect until it is more advanced (Lebow and Lebow 2018). The smaller dimensions and soil moisture likely also contributed to boron depletion from stakes relative to decking. Previous research found that the extent of boron leaching is greatly influenced by specimen dimensions (Mitsuhashi et al. 2007). Soil in the Mississippi test site also supports at least one type of copper-tolerant fungus that can cause rapid failure of copper treated stakes that do not contain a co-biocide, or if that co-biocide has been depleted by leaching.

\section{CZDP decking}

Decking specimens treated with CZDP exhibited no evidence of decay until the year 17 when a fungal fruiting body was observed on one the specimens treated with a $0,66 \%$ CZDP solution concentration (Figure $3)$. No other decay was evident in other specimens treated with $0,66 \%$ CZDP. Similarly, specimens treated with $1,32 \%$ CZDP or $1 \%$ CCA-C have shown no evidence of fungal decay after 17 years of exposure.

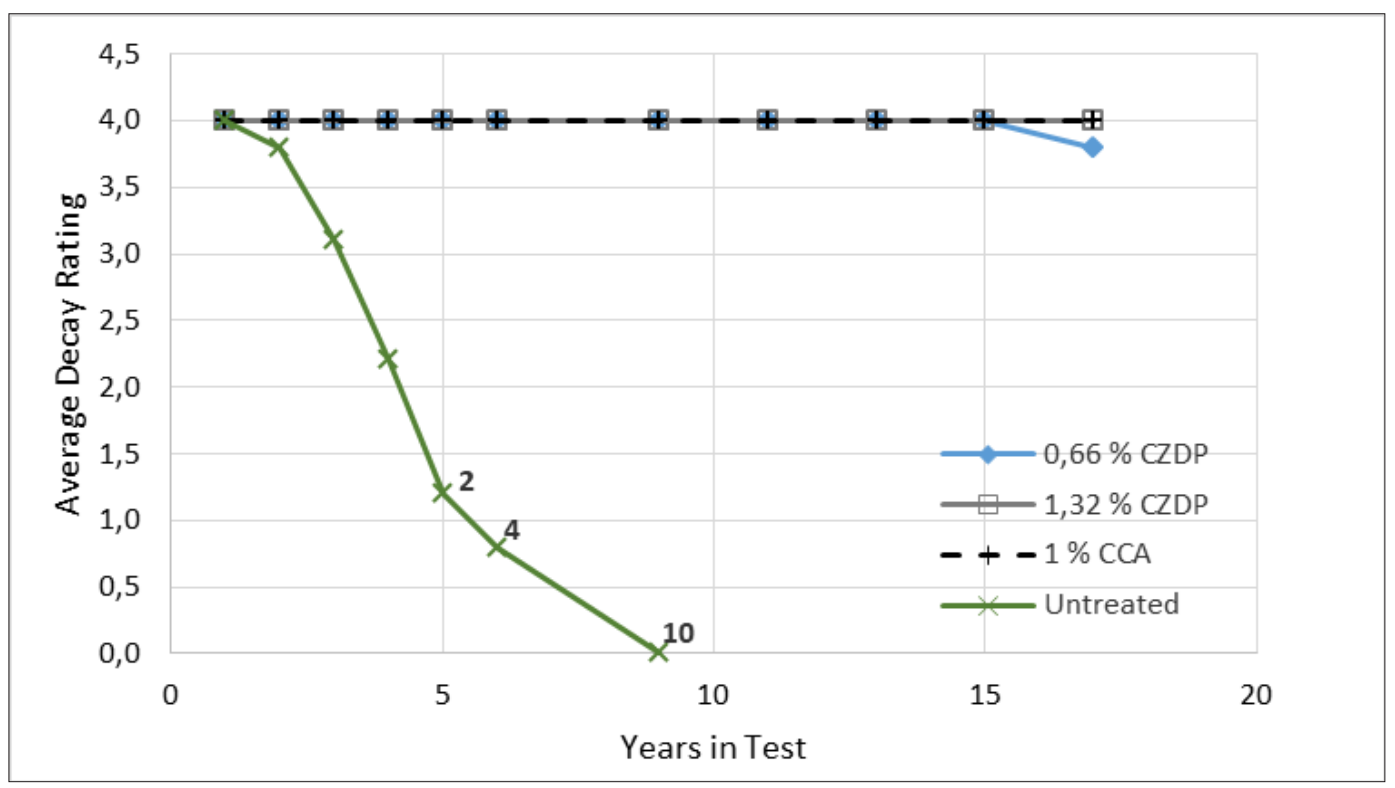

Figure 3: Average decay rating for untreated, CZDP-treated or CCA-treated specimens. Values adjacent to data points show cumulative number of failed specimens (if any).

The CZDP treatments appeared to provide a benefit in surface appearance relative to untreated specimens or specimens treated with $1 \%$ CCA-C (Figure 4). The improved mold inhibition is likely a function of zinc, dimethyl cocoamine and/or propionic acid, all of which have been used as components of moldicide formulations (Clausen and Yang 2007, Hansen 2008). 


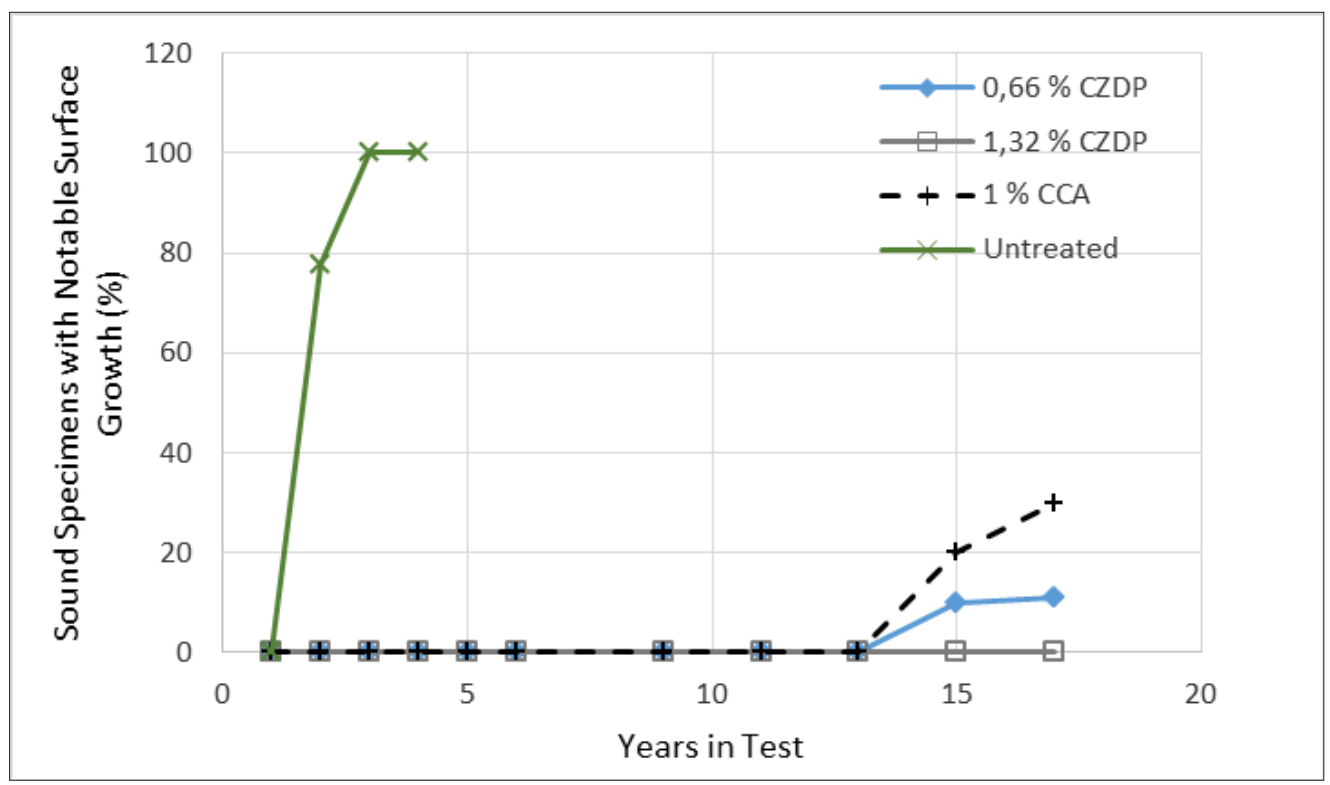

Figure 4: Percent of untreated, CZDP-treated or CCA-treated specimens with notable non-decay surface microbial growth at each inspection.

Although the CZDP treated decking specimens reported in this study have been relatively decay resistant, stake specimens exposed in Mississippi (Lebow et al. 2012) were less durable (Table 5). At least one failure occurred in 4 or 5 years in stakes treated with equivalent CZDP formulations, although it did take several more years for decay to be observed in $25 \%$ of the stakes treated with the 1,32 \% CZDP concentration. It is likely that early failures in CZDP treated stakes were caused by a copper-tolerant fungus which has been frequently observed at the Mississippi test site (Lebow et al. 2012). That copper-tolerant fungus has not been reported in the Wisconsin decking specimens, perhaps because copper-tolerant fungi are thought to be less capable of degrading copper-treated wood above-ground (Choi et al. 2002, Ohno et al. 2015).

Table 5: Comparison of years to reach three decay conditions for above-ground decking (this paper) and inground stake specimens (previous studies ${ }^{\mathrm{a}}$ ).

\begin{tabular}{|c|c|c|c|c|c|c|}
\hline \multirow{3}{*}{$\begin{array}{l}\text { Preservative } \\
\text { Formulation }\end{array}$} & \multicolumn{6}{|c|}{ Years to Reach Decay Condition of: } \\
\hline & \multicolumn{2}{|c|}{ One Specimen with Decay } & \multicolumn{2}{|c|}{ One Failed Specimen } & \multicolumn{2}{|c|}{ Decay in $25 \%$ of Specimens } \\
\hline & Decking & Stakes & Decking & Stakes & Decking & Stakes \\
\hline $0,93 \% \mathrm{BC}$ & 5 & 1 & 7 & 1 & 7 & 1 \\
\hline $1,40 \% \mathrm{BC}$ & 10 & 1 & 10 & 2 & 15 & 1 \\
\hline $2,34 \% \mathrm{BC}$ & 18 & 1 & $\mathrm{ND}^{\mathrm{b}}$ & 2 & ND & 2 \\
\hline $1 \% \mathrm{CCA}-\mathrm{C}$ & ND & ND & ND & ND & ND & ND \\
\hline Untreated & 3 & 1 & 7 & 1 & 4 & 1 \\
\hline $0,66 \%$ CZDP & 17 & 3 & ND & 5 & ND & 5 \\
\hline $1,32 \%$ CZDP & ND & 4 & ND & 4 & ND & 9 \\
\hline $1 \% \mathrm{CCA}-\mathrm{C}$ & ND & ND & ND & ND & ND & ND \\
\hline Untreated & 2 & 1 & 5 & 1 & 3 & 1 \\
\hline
\end{tabular}

${ }^{a}$ BC stake test data from Lebow et al. 2009; CZDP stake test data from Lebow et al. 2012.

${ }^{b} \mathrm{ND}$ indicates not determined because condition has not yet been reached.

The laboratory leaching study indicates that much of the boron would have been depleted from the $\mathrm{BC}$ decking within a few years, leaving copper as the only biocide. The $\mathrm{BC}$ specimens appear to confirm that relatively low copper concentrations can provide substantial protection for decking exposed in a moderate climate. Although studies have indicated that residential decks are replaced after an average of only 9 - 13 years, often for aesthetic reasons (Alderman et al. 2003, Bailey et al. 2004, Bolin and Smith 2011), it is likely that many 
consumers expect greater durability. Decay was first observed in one specimen treated with the highest $(2,34$ $\%) \mathrm{BC}$ concentration after 18 years, and the lower $(0,66 \%)$ CZDP concentration after 17 years. However, it should be noted that the specimen configuration in these decking tests did not incorporate moisture-trapping features that might be encountered in some types of construction. The decking specimens are also exposed in an open area with full sun which likely promotes drying after rainfall events and minimized accumulation of leaf litter or other organic detritus that might contribute to the decay hazard. Thus, wood in use above-ground might be subjected to decay hazards more severe than those in this study. The results also highlight the great difference in above ground and ground contact decay hazard. This is perhaps most evident with the BC formulation which failed rapidly in ground contact at all retentions.

The CZDP formulation appeared to have the potential to be more effective than the BC formulation, at least in ground contact (Lebow et al. 2012). The 2,34 \% BC and 0,66 \% CZDP formulations have similar copper concentrations, but the $0,66 \%$ CZDP treated stakes were more durable (Lebow et al. 2012). This is not surprising given the presence of zinc and dimethylcocoamine in the CZDP formulation. The BC formulation did contain borax, but it is likely that the boron was leached from the stakes within the first 2 years (Lebow and Halverson 2008). Differences in efficacy between 2,34 \% BC and 0,66 \% CZDP are not yet evident in the decking specimens.

\section{CONCLUSIONS}

Boron copper (BC) and copper zinc dimethylcocoamine propanoic acid (CZDP) preservative formulations substantially improved decking durability in an above ground exposure under moderate conditions for decay development. It appears that CZDP formulation may be more effective than the $\mathrm{BC}$ formulation at equivalent concentrations, but this trend is not yet fully evident in the decking specimens. These decking studies confirm that relatively low copper concentrations can provide substantial protection for decking and suggest that less strongly fixed preservative systems may still be suitable out of direct soil contact. Further evaluations are planned.

\section{ACKNOWLEDGEMENTS}

The authors would like to acknowledge Steven Halverson for assistance in preparation and installation of test specimens.

\section{REFERENCES}

Ahmed, B.M. French, J.R.J.; Vinden, P. 2004. Evaluation of borate formulations as wood preservatives to control subterranean termites in Australia. Holzforschung 58(4): 446-454. https://doi.org/10.1515/ HF.2004.068.

Alderman, D.; Smith, R.; Araman, P.A. 2003. A profile of CCA-treated lumber removed from service in the southeastern United States decking market. Forest Prod J 53(1): 38-45. https://www.fs.usda.gov/treesearch/pubs/5375.

AWPA. 2019. Book of Standards. American Wood Protection Association: Birmingham, Alabama, USA. $642 \mathrm{p}$.

Bailey, D.S.; Smith, R.L.; Araman, P.A. 2004. An Analysis of the Physical Properties of Recovered CCA-Treated Wood from Residential Decks. Wood Fiber Sci 36(2): 278-288. https://wfs.swst.org/index.php/ wfs/article/view/1489.

Barnes, H.M.; Amburgey, T.L.; Sanders, M.G. 2004. Performance of zinc-based preservative systems in ground contact. Wood Des Focus 14: 13-17.

Bolin, C.A.; Smith, S. 2011. Life cycle assessment of ACQ-treated lumber with comparison to wood plastic composite decking. J Clean Prod 19 (6-7): 620-629. https://doi.org/10.1016/j.jclepro.2010.12.004.

Butcher, J.A.; Preston, A.F.; Drysdale, J. 1977. Initial screening trials of some quaternary ammonium compounds and amine salts as wood preservatives. Forest Prod J 27(7): 19-22. 
Carll, C.G. 2009. Decay hazard (Scheffer) index values calculated from 1971-2000 climate normal data. General Technical Report FPL-GTR-179. Madison, WI: U.S. Department of Agriculture, Forest Service, Forest Products Laboratory. USA. 17p. https://www.fs.usda.gov/treesearch/pubs/35056.

Choi, S.M.; Ruddick, J.N.R.; Morris, P.I. 2002. The copper tolerance of mycelium vs spores for two brown rot fungi. . In Proceedings IRG Annual Meeting, IRG/WP 02-10422. The International Research Group on Wood Protection: Stockholm, Sweden, $4 \mathrm{p}$.

Clausen C.A.; Coleman R.D.; Yang V.W. 2010. Fatty acid-based formulations for wood protection against mold and sapstain. Forest Prod J 60(3): 301-304. https://www.fs.usda.gov/treesearch/pubs/37170.

Clausen, C.A.; Yang, V.W. 2007. Multi-component biocide protects wood from fungi and insects in UC2 applications. In Proceedings, 103 ${ }^{\text {rd }}$ annual meeting of the American Wood Protection Association. 103:31-35. St. Louis, Missouri, USA. American Wood Protection Association, Birmingham, AL, USA. https://www. fs.usda.gov/treesearch/pubs/32720.

De Groot, R.C.; Stroukoff, M. 1988. Efficacy of alternative preservatives used in dip treatments for wood boxes. FPL-RP-481, U.S. Department of Agriculture, Forest Service, Forest Products Laboratory, Madison, WI, USA. 21p. https://www.fpl.fs.fed.us/products/publications/specific_pub.php?posting_id=16256\&header $\_$id $=$p.

Drysdale, J.A. 1994. Boron treatments for the preservation of wood-A review of efficacy data for fungi and termites. In Proceedings IRG Annual Meeting, IRG/WP 94-30037. The International Research Group on Wood Protection: Stockholm, Sweden. 21p.

Freeman, M.H.; McIntyre, C.R. 2008. A Comprehensive Review of Copper Based Wood Preservatives with a Focus on New Micronized or Dispersed Copper Systems. Forest Prod J 58(11): 6-27.

Hansen, K. 2008. Molds and moldicide formulations for exterior paints and coatings. In Development of Commercial Wood Preservatives, Efficacy, Environmental and Health Issues. Chapter 11: 198-213. Schultz, T.P.; Militz, H.; Freeman, M.H.; Goodell, B.; Nicholas, D.D. (Eds.). ACS Symposium Series 982. American Chemical Society. Washington, D.C., USA. https://pubs.acs.org/doi/abs/10.1021/bk-2008-0982.ch011.

Kirker, G.; Winandy, J. 2014. Above Ground Deterioration of Wood and Wood-Based Materials. In Deterioration and Protection of Sustainable Biomaterials. Chapter 6: 114-129. Schultz, T.P; Goodell, B.; Nicholas, D.D. (Eds.). ACS Symposium Series 1158. American Chemical Society: Washington, D.C., USA. https:// pubs.acs.org/doi/full/10.1021/bk-2014-1158.ch006.

Lebow, S.; Anthony, R.W. 2012. Guide for use of wood preservatives in historic structures. General Technical Report FPL-GTR-217. U.S. Department of Agriculture, Forest Service, Forest Products Laboratory. Madison, WI, USA. 59p. https://www.fs.usda.gov/treesearch/pubs/42091.

Lebow, S.; Halverson, S. 2008. Comparison of methods for evaluating ground-contact copper preservative depletion. In Proceedings IRG Annual Meeting. The International Research Group on Wood Protection 104: Portland, OR, USA: 55-60: https://www.fs.usda.gov/treesearch/pubs/33203.

Lebow, S.T.; Hatfield, C.A.; Abbott, W. 2005a. Treatability of SPF framing lumber with CCA and borate preservatives. Wood Fiber Sci 37(4): 605-614. https://wfs.swst.org/index.php/wfs/article/view/743.

Lebow, S.T.; Ross, R.J.; Zelinka, S.L. 2014. Evaluation of Wood Species and Preservatives for Use in Wisconsin Highway Sign Posts. USDA Forest Service, Forest Products Laboratory, General Technical Report, FPL-GTR-231. 51p. https://www.fs.usda.gov/treesearch/pubs/46200.

Lebow, S.T.; Shupe, T.; Woodward, B.; Via, B.; Hatfield, C.A. 2006. Formosan and native subterranean termite attack of pressure treated SPF wood species in Louisiana. Wood Fiber Sci 38(4): 609-620. https://wfs. swst.org/index.php/wfs/article/view/1330.

Lebow, S.; Woodward, B.; Crawford, D.; Abbott, W. 2005b. Resistance of borax-copper treated wood in aboveground exposure to attack by Formosan subterranean termites. Res. Note FPL-RN-0295. U.S. Department of Agriculture, Forest Service, Forest Products Laboratory. Madison, WI, USA. 4p. https://www.fs.usda. gov/treesearch/pubs/20962. 
Lebow, S.T.; Lebow, P.K. 2018. Internal moisture content and temperature of standardized aboveground wood durability test specimens. Res. Paper FPL-RP-694. U.S. Department of Agriculture, Forest Service, Forest Products Laboratory. Madison, WI, USA. 16p. https://www.fs.usda.gov/treesearch/pubs/56748.

Lebow, S.T.; Lebow, P.K.; Woodward, B.M.; Halverson, S.A.; Abbott, W.; West, M.M. 2009. Efficacy of a borax-copper preservative in exposed applications. Res. Paper FPL-RP-655. U.S. Department of Agriculture, Forest Service, Forest Products Laboratory. Madison, WI, USA. 11p. https://www.fs.usda.gov/treesearch/ pubs/33881.

Lebow, S.; Woodward, B.; Halverson, S.; West, M. 2012. Field tests of the efficacy of zinc and fatty amine in preventing colonization by copper-tolerant fungi. Int Biodeter Biodegrad 70: 74-78. https://doi. org/10.1016/j.ibiod.2012.02.003.

Manning, M.J. 2008. Borate wood preservatives: the current landscape. In Development of Commercial Wood Preservatives, Efficacy, Environmental and Health Issues. Chapter 26: 440-457. Schultz, T.P.; Militz, H.; Freeman, M.H.; Goodell, B.; Nicholas, D.D. (Eds.). ACS Symposium Series 982. American Chemical Society. Washington, DC, USA. https://pubs.acs.org/doi/10.1021/bk-2008-0982.ch026.

Mitsuhashi, J.; Love, C.S.; Freitag, C.; Morrell, J.J. 2007. Migration of boron from Douglas-fir lumber subjected to simulated rainfall. Forest Prod J 57(12): 52-57.

Ohno, K.M.; Clausen, C.A.; Green III, F.; Diehl, S.V. 2015. Insights into the mechanism of copper-tolerance in Fibroporia radiculosa: The biosynthesis of oxalate. Int Biodeter Biodegrad 105: 90-96. https://doi. org/10.1016/j.ibiod.2015.08.016.

Ohno, K.M.; Clausen, C.A.; Green III, F.; Stanosz, G. 2016. The copper-transporting ATPase pump and its potential role in copper-tolerance. In Proceedings IRG Annual Meeting, IRG/WP 16-10859. The International Research Group on Wood Protection: Stockholm, Sweden, 15p.

Preston, A.F. 1983. Dialkylmethylammonium halides as wood preservatives. J Am Oil Chem Soc 60(3): 567-570. https://doi.org/10.1007/BF02679788.

Rak, J.; Unligil, H. 1978. Fungicidal Efficacy of Ammoniacal Copper and Zinc Arsenic Preservatives Tested by Soil-Block Cultures. Wood Fiber Sci 9(4): 270-275. https://wfs.swst.org/index.php/wfs/article/ view/2063.

Sheaffer, C.C.; Clark, N.A. 1975. Effects of organic preservatives on the quality of aerobically stored high moisture baled hay. Agron J 67(5): 660-662. https://doi.org/10.2134/agronj1975.000219620067000500 19x.

Suhr, K.I.; Nielsen, P.V. 2004. Effect of weak acid preservatives on growth of bakery product spoilage fungi at different water activities and pH values. Int J Food Microbiology 95: 67-78. https://doi.org/10.1016/j. ijfoodmicro.2004.02.004.

Taylor, A.; Lloyd, J. 2009. Phytosanitation of railway crossties with a hot borate solution immersion treatment. Forest Prod J 59(4): 76-78.

West, H.M. 2004. Metal Salt-Fatty Amine Complex Wood Protection. U.S. Patent and Trademark Office, Washington, DC, USA. 6746523B1, June 8, 2004. https://patents.google.com/patent/US6746523B1/en.

Williams, D.A.; Looney, J.R.; Sullivan, D.S.; Bourland, B.J.; Haselgrave, J.H.; Clewlon, P.J.; Carruthers, N.; O'Brien, T.M. 1994. Amine Derivatives as Corrosion Inhibitors. U.S. Patent and Trademark Office, Washington, DC, USA 5322630A., June 21, 1994. https://patents.google.com/patent/US5322630A/en.

Woodward, B.; Abbott, W.; West, M. 2002. Retreatment of spent creosote-treated wood with copper hydroxide and sodium tetraborate. In Proceedings of the American Wood Preservers Association 98: 58-61. Memphis, Tennessee, USA. 